\title{
Immunization Coverage in A Rural Community in Southwestern Nigeria
}

Bosede Ehelami Adebayo, Regina Eziuka Oladokun* and Felix Olukayode Akinbami

University College Hospital, Ibadan, Nigeria

\begin{abstract}
Background and aim: Poor immunization coverage especially in rural areas has led to a high burden of vaccine preventable diseases in children. The study assessed routine immunization coverage and its determinants in a rural community in South Western Nigeria.
\end{abstract}

Methods: A descriptive cross-sectional survey using the WHO cluster survey design was conducted among children aged 12 to 23 months. Coverage was assessed by immunization cards.

Results: A total of 440 mothers were interviewed with a mean age of $27.9 \pm 5.7$ years. The mean age of the children was $17.3 \pm 3.7$ months. Full immunization was recorded among $130(29.5 \%)$ children and of these only $53.8 \%$ completed their immunization by 12 months. The highest and lowest vaccine coverage was observed for DPT1 $(90.2 \%)$ and Yellow fever $(55 \%)$ respectively. The commonest reasons for failure to immunize were; non availability of vaccines (40\%) and the mother being too busy $(24.2 \%)$. Predictors of immunization status included maternal education $(p=0.002)$, place of delivery $(p<0.001)$, family type $(p=0.04)$ and child's birth order $(p=0.03)$.

Conclusion: The immunization coverage rate among children in this rural community was sub-optimal and lower dropout rates may be achieved by making vaccines readily available. High female literacy levels and delivery in health facilities need to be promoted.

Keywords: Routine; Immunization; Coverage; Rural; Children

Abbreviations: HF: Health Facility; LGA: Local Government Area; PHC: Primary Health Centre

\section{Introduction}

Vaccine preventable diseases (VPDs) such as Measles, Tetanus, Tuberculosis, Poliomyelitis, Pertussis, Diphteria, Yellow fever and Hepatitis B contribute substantially to morbidity and mortality among children less than five years in developing countries [1]. It is estimated that about 2 million deaths occur globally each year from VPDs with approximately 1.5 million occurring in children under five years of age and constituting $15 \%$ of under five deaths [2]. In Nigeria, they account for $22 \%$ and $17 \%$ of under five mortality and morbidity respectively [3].

The World Health Organization (WHO), United Nations Children's' Fund (UNICEF), and National Programme on Immunization (NPI) guidelines stipulate that a child should receive four doses of Oral Polio Vaccine (OPV), three doses of Hepatitis B Vaccine, three doses of Diphtheria, Pertussis and Tetanus (DPT) vaccine and one dose each of Bacille Calmette - Guerin (BCG), measles and yellow fever vaccines [4]. Routine immunization with these vaccines is a cost effective way of reducing childhood morbidity and mortality in developing countries [5]. The prevention of these diseases in one child also has a positive ripple effect on the population as the immunized child will not transmit the disease to another child (herd immunity).

In 2008, the World Health Organization estimated that 1.5 million of deaths among children under five years were due to diseases that could have been prevented by routine vaccination, representing $17 \%$ of global total mortality in children under 5 years of age [6]. In the United States immunization has reduced the incidence of childhood vaccine preventable diseases by $98-100 \%$ [7]. The effective control of vaccine preventable diseases depend on the extent of immunization coverage achieved hence the estimation of the success of routine immunization by assessing the coverage rate. In Nigeria, the findings of the National Demographic Health Survey along with UNICEF showed a decline in the immunization coverage between 1990 and 1999 from about 30\% to $17 \%$ and a further gradual decline to $13 \%$ in 2003 [8,9]. The reasons adduced for this included poor coordination and planning, political instability, and continuing economic recession [10,11]. Effective monitoring and evaluation of childhood immunization programmes are necessary as in their absence, vaccination rates may dwindle unnoticed for some time before increased incidence of target diseases are observed.

Countries with low under five mortality figures have an inverse relationship with their immunization coverage rates. Sweden with immunization coverage of $98 \%$ has an under-five mortality rate of 4/1000; this is similar to that of Japan, France and the United States of America all with immunization coverage rates greater than $90 \%$ [12]. Developing countries like Nigeria with immunization coverage rates below $80 \%$ have under five mortality rates above 100/1000 [12]. Although high under five mortality rates may be understandable in war torn countries like Angola and Liberia, this is not the situation in Nigeria and thus it is imperative for health care delivery systems to identify why there is poor immunization coverage in that country.

There is paucity of published data on the immunization coverage in the communities in developing countries [13]. Some of the reports on immunization coverage surveys included both urban and rural data while some were carried out in rural communities. The need for the precise and accurate documentation of immunization rates and the possible causes of the poor coverage in specific regions to enable well directed (or targeted) interventions should help reduce under-five

*Corresponding author: Dr. Regina Eziuka Oladokun, Department of Paed iatrics, University College Hospital, Ibadan, Nigeria, Tel: 234803806 7511; E-mail: ginaoladokun@yahoo.com

Received May 24, 2012; Accepted August 17, 2012; Published August 22, 2012

Citation: Adebayo BE, Oladokun RE, Akinbami FO (2012) Immunization Coverage in A Rural Community in Southwestern Nigeria. J Vaccines Vaccin 3:143. doi:10.4172/2157-7560.1000143

Copyright: (c) 2012 Adebayo BE, et al. This is an open-access article distributed under the terms of the Creative Commons Attribution License, which permits unrestricted use, distribution, and reproduction in any medium, provided the original author and source are credited. 
mortality rates in these communities. This study was carried out to determine the immunization coverage of children in a rural community.

\section{Materials and Methods}

\section{Study area}

The study was conducted in Ogo-Oluwa Local Government Area (LGA) one of the rural communities in Oyo State, Southwestern Nigeria. According to the 2006 National Population Commission [14], the population of Oyo State was 5,580,894 with about $65 \%$ of the population living and working in rural areas. The main occupation in the rural areas is agriculture. Ogo-Oluwa LGA measures 451,951 sq km and has 10 political wards. The total population of Ogo-Oluwa is 65,198 and the target population for routine immunization is 2,608 (4\% of total population). There are 10 fixed posts for routine immunization ( 1 in each ward). Routine immunization services is held once a month in the Primary Health Care centres of eight of the wards, once forth nightly in one ward and once weekly in only one ward.

\section{Study population}

The study involved mothers of children aged 12-23 months in Ogo-Oluwa LGA of Oyo State. In the case of a mother with more than one child within the age range, the younger child was recruited into the study as this gave a better reflection of the current practice of the mother [15].

\section{Study design}

A descriptive cross sectional survey of mothers of children aged 1223 months in Ogo-Oluwa LGA of Oyo State.

\section{Sampling technique}

The minimum sample size of four hundred and thirty four children was determined using the WHO formula for cluster survey sampling [15].

In the cluster sampling method used, in the first stage, OgoOluwa, was randomly selected from the rural local government areas by balloting. A list of all the wards in Ogo-Oluwa LGA was obtained from the LGA secretariat and every ward was included in the study. In the second stage, a list of the settlements in each of the wards was also obtained with the total number of settlements varying between seven and twelve in each ward. Half of the total number of settlements was selected randomly from each ward by balloting (each settlement was taken as a cluster). Sample size was estimated following the standard procedure for using cluster sampling for assessment of immunization coverage [15]. Having adjusted for a target population of less than 10,000 the estimated sample size was 434 . A total of 75 clusters were studied and the number of children selected per cluster was seven.

The third stage involved the selection of households; the approximate geographic centre of the settlement cluster was located with the assistance of elderly members of the settlement. One of the four cardinal directions (North, South, East and West) from the centre was randomly selected by balloting. The household nearest to the centre in the selected direction was the first household visited. After visiting the first household, the second and subsequent households visited were the ones nearest to the first until the desired sample size from that cluster was obtained.

The nearest household was defined as the household reachable in the shortest time on foot from the household just visited. When there were two or more households equally near to the one just visited, the one on the immediate right while standing in the doorway of the index house and looking out was selected. The youngest eligible child was selected in each household for the survey.

\section{Study instrument}

Data were collected by means of a semi-structured pretested questionnaire, which was interviewer administered. The questions were specific, as well as the required answers; hence there was very limited room for inter-observer errors. The information included age, sex, immunization data and reasons for non-immunization where necessary. Thirty three (33) children were excluded as a result of lack of verified immunization cards. The immunization status of the children obtained from the mothers was crosschecked with immunization records and only children whose immunization was verified with immunization cards were included in the study. The questionnaire was translated to Yoruba, the local language and was back translated to English with the translated versions matching well with the original version.

\section{Ethical issues}

Permission was obtained from the Primary Health Care coordinator of Ogo Oluwa LGA. Ethical approval was obtained from the ethical research committee of Oyo State Ministry of Health. Informed consent was obtained from mothers who participated in the study after a detailed explanation of the purpose of the study and the required assistance. Confidentiality was maintained during the course of the study by ensuring face to face interviews by each interviewer without a third party and information obtained during the study was kept confidential. All mothers with children who were not completely immunized were properly counseled and referred to the primary health care centre for immunization.

\begin{tabular}{|c|c|c|}
\hline Characteristics & n (440) & $\%$ \\
\hline \multicolumn{3}{|l|}{ Age group (years) } \\
\hline $15-19$ & 18 & 4.1 \\
\hline $20-24$ & 98 & 22.3 \\
\hline $25-29$ & 152 & 34.5 \\
\hline $30-34$ & 99 & 22.5 \\
\hline$\geq 35$ & 73 & 16.6 \\
\hline \multicolumn{3}{|l|}{ Family type } \\
\hline Monogamy & 335 & 76.1 \\
\hline Polygamy & 102 & 23.2 \\
\hline Single parent & 3 & 0.7 \\
\hline \multicolumn{3}{|l|}{ Level of education } \\
\hline None & 66 & 15.0 \\
\hline Primary & 130 & 29.5 \\
\hline Junior secondary & 107 & 24.3 \\
\hline Senior secondary & 131 & 29.8 \\
\hline Post secondary & 6 & 1.4 \\
\hline \multicolumn{3}{|l|}{ Occupation } \\
\hline Farming & 178 & 40.5 \\
\hline Petty trading & 192 & 43.6 \\
\hline Housewife & 35 & 8.0 \\
\hline Others* & 35 & 7.9 \\
\hline \multicolumn{3}{|l|}{ Religion } \\
\hline Christianity & 341 & 77.5 \\
\hline Islam & 99 & 22.5 \\
\hline
\end{tabular}

*Teachers, patent medicine dealers, hairdressers and tailors

Table 1: Socio-demographic characteristics of the respondents (mothers) 


\begin{tabular}{|l|c|c|}
\hline Characteristics & $\mathbf{N = 4 4 0}$ & $\%$ \\
\hline Sex & 212 & 48.2 \\
\hline Male & 228 & 51.8 \\
\hline Female & & \\
\hline Birth order & 81 & 18.4 \\
\hline 1 & 94 & 21.4 \\
\hline 2 & 122 & 27.7 \\
\hline 3 & 143 & 32.5 \\
\hline$\geq 4$ & & \\
\hline Place of delivery & $\mathbf{2 3 2}$ & $\mathbf{5 2 . 7}$ \\
\hline Health facility & 149 & 64.2 \\
\hline Primary Health Care (PHC) & 8 & 3.4 \\
\hline Other government hospitals & 73 & 31.5 \\
\hline Private hospital & 2 & 0.9 \\
\hline Missionary hospital & $\mathbf{2 0 8}$ & $\mathbf{4 7 . 3}$ \\
\hline Outside health facility & 23 & 11.1 \\
\hline Church & 185 & 88.9 \\
\hline Home & & \\
\hline
\end{tabular}

Table 2: Characteristics of the index children.

\begin{tabular}{|l|c|c|}
\hline Antigen & $\mathbf{n}$ & $\%$ \\
\hline BCG & 324 & 73.6 \\
\hline DPT1 & 397 & 90.2 \\
\hline DPT2 & 339 & 77.0 \\
\hline DPT3 & 337 & 76.6 \\
\hline OPV0 & 293 & 66.6 \\
\hline OPV1 & 385 & 87.5 \\
\hline OPV2 & 334 & 75.9 \\
\hline OPV3 & 338 & 76.8 \\
\hline HBV1 & 376 & 85.5 \\
\hline HBV2 & 371 & 84.3 \\
\hline HBV3 & 314 & 71.4 \\
\hline Measles & 286 & 65.0 \\
\hline Yellow fever & 242 & 55.0 \\
\hline
\end{tabular}

Table 3: Distribution of immunization coverage of children aged $12-23$ by vaccine type $(\mathrm{N}=440)$.

\section{Data management}

The data obtained were entered into a computer and analyzed with SPSS version 11.0. Tables, graphs and charts have been used to report descriptive statistics. In testing for associations, cross tabulation was done and chi- squared statistics has been used for qualitative variables. The level of significance was established at $p$-value $<0.05$. Multivariate analysis was used to determine the sociodemographic factors associated with immunization coverage.

\section{Results}

\section{Socio-demographic characteristics of mothers and index children}

The mean age of the mothers was $27.9 \pm 5.7$ years. Table 1 shows the socio-demographic characteristics of mothers. Majority, 152(34.5\%) were in the 25-29 years age group while the least represented age group was 15-19 years accounting for 18(4.1\%) mothers. Over half, $238(54.1 \%)$ had secondary education, $130(29.5 \%)$ primary and $66(15.0 \%)$ had no formal education. Only six (1.4\%) mothers had post secondary education.

The characteristics of the index children and their places of delivery are shown in table 2 . Two hundred and twenty-eight $(51.8 \%)$ were females while $212(48.2 \%)$ were males giving a female: male ratio of
1.1:1. About half, 232(52.7\%) of the children were delivered at a health facility. Among those that were delivered at a health facility, 149(64.2\%) were delivered at Primary Health Centres (PHC) and among those delivered outside a health facility, 185(88.9\%) were delivered at home.

\section{Immunization coverage of index children}

Table 3 shows the immunization coverage of children aged 12-23 months by vaccine type. Only DPT1, OPV1, HBV1 and HBV2 had 80\% coverage and above. The antigen with the highest coverage was DPT1, $(90.2 \%)$ while the lowest was yellow fever (55.0\%).

\section{Dropout rate by vaccine type}

Figure 1 shows dropout rate of children of 12-23 months by vaccine types. DPT3/Yellow fever had the highest dropout rate of $39.0 \%$, followed by BCG/yellow fever, $25.3 \%$ and the least was BCG/measles, $11.7 \%$.

\section{Immunization status of index children}

One hundred and thirty $(29.5 \%)$ children were fully immunized, 289(65.7\%) were partially immunized and 21(4.8\%) were not immunized. Among the 130 children who were fully immunized at the time of the study, 54\% completed their immunization before 12 months.

\section{Timeliness for immunization}

Figure 2 shows the proportions of children who received each vaccine at recommended ages according to the national immunization

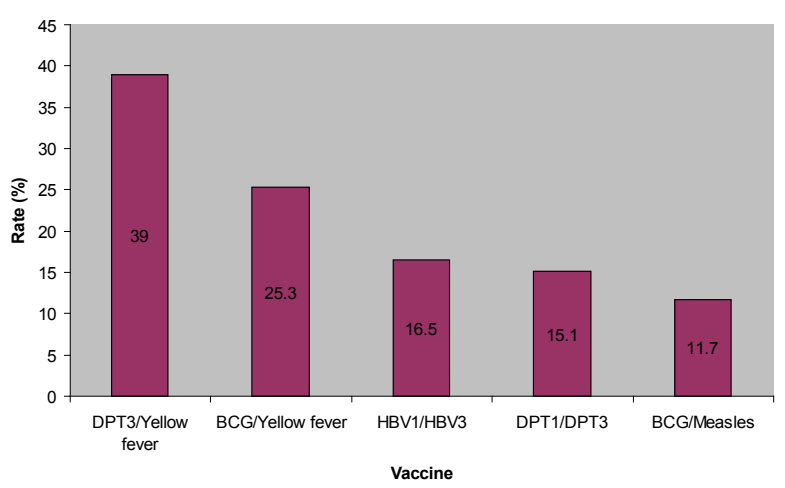

Figure 1: Dropout rate by vaccine type.

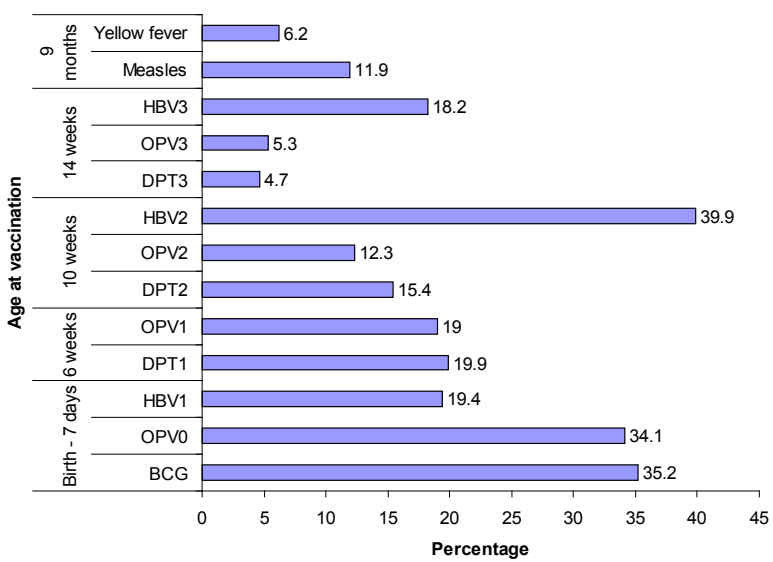

Figure 2: Percentage of children who received vaccine at recommended age. 


\begin{tabular}{|l|c|}
\hline Reason & No (\%) \\
\hline Obstacles & \\
\hline Vaccine not available & $124(40.0)$ \\
Mother too busy & $75(24.2)$ \\
Place of immunization too far & $68(21.9)$ \\
Travelled & $25(8.1)$ \\
Family problem, including illness of mothers & $17(5.5)$ \\
Vaccinator absent & $16(5.2)$ \\
Time of immunization not convenient & $14(4.5)$ \\
\hline Child ill-not brought & $13(4.2)$ \\
\hline Child ill-brought not given immunization & $3(1.0)$ \\
\hline Long waiting time & $1(0.3)$ \\
\hline Lack of information & \\
\hline Unaware of need for immunization & $47(15.2)$ \\
\hline Unaware of need to return for $2^{\text {nd }}$ or 3 $^{\text {rd }}$ dose & $23(7.4)$ \\
\hline Fear of side reactions & $17(5.5)$ \\
\hline Place and/or time of immunization unknown & $16(5.2)$ \\
\hline Wrong ideas about contraindications & $4(1.3)$ \\
\hline Lack of motivation & \\
\hline Postponed until another time & $35(11.3)$ \\
\hline No faith in immunization & $1(0.3)$ \\
\hline Rumours & 0 \\
\hline
\end{tabular}

Table 4: Stated reasons for incomplete or no immunization $(\mathrm{N}=310)$.

programme schedule. The timeliness for receiving HBV2 was the highest, recorded at $39.9 \%$ while the lowest was recorded for DPT3, OPV3 and Yellow fever at 4.7\%, 5.3\% and 6.2\% respectively.

\section{Reasons for failure to immunize}

The major reasons for failure to immunize children were categorized into obstacles, lack of information and lack of motivation and are shown in table 4. Obstacles in all accounted for most of the reasons (72.3\%) for failure to immunize children while lack of information and motivation accounted for $23.5 \%$ and $4.2 \%$ respectively.

\section{Association between socio-demographic variables and immunization status of children}

Table 5 shows the bivariate analysis of socio-demographic variables and immunization status of children. A significant association was found between immunization status and child's birth order and age; place of birth, family type, mother's level of education, immunization centre at settlement as well as distance of health centre from settlement. 92(39.7\%) of the children who were delivered at health facilities were fully immunized compared with $38(18.3 \%)$ of those that delivered outside of health facilities (church and home) $(\mathrm{p}<0.001)$. Also, $33.4 \%$ of mothers with some education had their children fully immunized compared with $7.6 \%$ of those without formal education $(\mathrm{p}<0.001)$. Mothers' age, marital status, occupation and religion and child's gender were not significantly associated with immunization status $(\mathrm{p}>0.05)$.

\section{Socio-demographic predictors of complete immunization status on multivariate analysis}

Table 6 shows the predictors of complete immunization status on multivariate analysis. Variables in the logistic regression model included the age of index children, mothers' level of education, birth order, family type, place of delivery, availability and distance of health facility offering immunization. After adjusting for confounders, child's birth order, mothers' level of education, family type and place of delivery were found to be statistically significant predictors of being fully immunized. Mothers without formal education were less likely (95\% CI $=0.085-0.586 ; \mathrm{p}=0.002)$ to have fully immunized children compared with those with some education (primary education and above). Children delivered at health facilities were 2.3 times more likely (95\% CI=1.431-3.759; $\mathrm{p}<0.001)$ to complete immunization compared with those delivered outside health facilities (churches and homes). However, the age of children, availability of immunization centres and distance of health facilities from place of residence were not significant predictors. Children aged $12-15$ months were less likely $(95 \% \mathrm{CI}=0.338$ $1.005 ; \mathrm{p}=0.052$ ) to be fully immunized compared to those between 20 23 months old.

\section{Discussion}

This study which assessed the immunization coverage in a rural community in Nigeria showed that only $29.5 \%$ of the children were fully immunized. There were variations in the coverage rate for individual vaccines, timeliness for vaccines was poor and the drop-out rates were

\begin{tabular}{|c|c|c|c|c|c|}
\hline \multirow[t]{2}{*}{ Characteristics } & \multicolumn{2}{|c|}{ Fully immunized } & \multirow[t]{2}{*}{$\mathbf{X}^{2}$} & \multirow[t]{2}{*}{$\mathbf{P}$} & \multirow[t]{2}{*}{ OR(95\% Cl) } \\
\hline & Yes & No & & & \\
\hline \multicolumn{6}{|l|}{ Child's gender } \\
\hline Male & $64(30.2)$ & 148(69.8) & 0.08 & 0.78 & $1.06(0.71-1.60)$ \\
\hline Female & $66(28.9)$ & 162(71.1) & & & \\
\hline \multicolumn{6}{|l|}{ Child's birth order } \\
\hline$<3$ & 65 (37.1) & $110(62.9)$ & 8.06 & 0.005 & $1.82(1.20-2.75)$ \\
\hline$\geq 3$ & $65(24.5)$ & $200(75.5)$ & & & \\
\hline \multicolumn{6}{|l|}{ Child's place of birth } \\
\hline Health centre & $92(39.7)$ & $140(60.3)$ & 24.10 & $<0.001$ & $2.94(1.90-4.56)$ \\
\hline Outside health centre & $38(18.3)$ & $170(81.7)$ & & & \\
\hline \multicolumn{6}{|l|}{ Child's age (months) } \\
\hline $12-15$ & $36(22.5)$ & $124(77.5)$ & 6.00 & 0.05 & Not done \\
\hline $16-19$ & $45(33.8)$ & $88(66.2)$ & & & \\
\hline $20-23$ & 49 (33.3) & $98(66.7)$ & & & \\
\hline \multicolumn{6}{|l|}{ Mother's age (years) } \\
\hline $15-19$ & $5(27.8)$ & 13(72.2) & 0.58 & 0.75 & Not done \\
\hline $20-34$ & $106(30.4)$ & 243(69.6) & & & \\
\hline$\geq 35$ & $19(26.0)$ & $54(74.0)$ & & & \\
\hline \multicolumn{6}{|l|}{ Family type } \\
\hline Monogamous & $110(32.8)$ & $225(67.2)$ & 6.55 & 0.011 & $2.00(1.17-3.44)$ \\
\hline Polygamous & $20(19.6)$ & $82(80.4)$ & & & \\
\hline \multicolumn{6}{|l|}{ Level of education } \\
\hline No formal & $5(7.6)$ & 61(92.4) & 18.00 & $<0.001$ & $0.16(0.06-0.42)$ \\
\hline Some education & $125(33.4)$ & $249(66.6)$ & & & \\
\hline \multicolumn{6}{|l|}{ Marital status* } \\
\hline Never married ${ }^{* *}$ & $1(14.3)$ & $6(85.7)$ & Fisher' & 0.68 & $0.39(0.47-3.30)$ \\
\hline Ever married & $129(29.8)$ & $304(70.2)$ & Exact & & \\
\hline \multicolumn{6}{|l|}{ Occupation } \\
\hline $\begin{array}{l}\text { Unemployed } \\
\text { (housewives) }\end{array}$ & $12(34.3)$ & $23(65.7)$ & 0.41 & 0.52 & $1.27(0.61-2.63)$ \\
\hline Employed & 118(29.1) & $287(70.9)$ & & & \\
\hline \multicolumn{6}{|l|}{ Religion } \\
\hline Christianity & $101(29.6)$ & $240(70.4)$ & 0.004 & 0.95 & $1.02(0.62-1.66)$ \\
\hline Islam & $29(29.3)$ & $70(70.7)$ & & & \\
\hline \multicolumn{6}{|l|}{$\begin{array}{l}\text { Immunization centre } \\
\text { at settlement }\end{array}$} \\
\hline Available & $108(34.6)$ & 204(65.4) & 13.24 & $<0.001$ & $2.55(1.52-4.27)$ \\
\hline Not available & $22(17.2)$ & $106(82.8)$ & & & \\
\hline \multicolumn{6}{|l|}{$\begin{array}{l}\text { Distance of health } \\
\text { centre from place of } \\
\text { residence }\end{array}$} \\
\hline$<5$ & $109(34.5)$ & 207(65.5) & 13.19 & $<0.001$ & $2.58(1.53-4.36)$ \\
\hline$\geq 5$ & $21(16.9)$ & 103(83.1) & & & \\
\hline
\end{tabular}

Table 5: Association between socio-demographic characteristics and immunization status of children. 


\begin{tabular}{|l|l|l|l|}
\hline Variables & Odds ratio & 95\% confidence interval & P-value \\
\hline Age (Index children) & & & \\
\hline $12-15$ & 0.583 & $0.338-1.005$ & 0.052 \\
\hline $16-19$ & 1.094 & $0.642-1.877$ & 0.734 \\
\hline $20-23$ & 1.000 & & \\
\hline Mothers' level of education & & & $0.002^{*}$ \\
\hline No formal & 0.224 & $0.085-0.586$ & \\
\hline Primary and above & 1.000 & & $0.029^{*}$ \\
\hline Birth order & & & \\
\hline$<3$ & 1.646 & $1.054-2.571$ & $0.040^{*}$ \\
\hline$\geq 3$ & 1.000 & & \\
\hline Family type & & & \\
\hline Monogamous & 1.827 & $1.028-3.247$ & $<0.001^{*}$ \\
\hline Polygamous & 1.000 & & \\
\hline Delivery place & & & \\
\hline Health facility & 2.320 & $1.431-3.759$ & \\
\hline Outside HF & 1.000 & & 0.72 \\
\hline Availability of HF & & & \\
\hline Yes & 1.372 & $0.243-7.738$ & \\
\hline No & 1.000 & & \\
\hline Distance to HF & & $0.215-7.166$ & \\
\hline$<5$ km & 1.241 & & \\
\hline$\geq 5$ km & 1.000 & & \\
\hline & & & \\
\hline
\end{tabular}

Table 6: Multivariate analysis of socio-demographic predictors of fully immunized status.

high. The commonest reason for failure to immunize children was non-availability of vaccines and the most important predictor of the immunization status is delivery in a health facility.

The immunization coverage of $29.5 \%$ obtained from this study was low. One of the strengths of this study is that the immunization status of each subject was confirmed by immunization cards. The latest national immunization coverage survey which was carried out in 2010 , reported that $53.01 \%$ of the children were fully immunized using card and history though only $18.38 \%$ were verified by card [16]. The use of immunization cards to assess coverage is necessary to verify the immunization status of a child as both overestimation and underestimation are possible depending on the maternal tendencies exhibited with regards to immunizations [17].

Though the target age group (12 to 23 months) and sampling methodology were similar, the national survey had included both urban and rural areas whereas our study was carried out in a purely rural community. It is important then to note that national estimates may not reflect the immunization coverage rates in individual communities and the continued changes in the social and political milieu of different communities requires that regular monitoring and evaluation of the immunization process should be continuous. Regardless of sample locale, immunization rates are abysmally low compared to the acceptable target set by the NPI of $80 \%$ [11]. Other rural communities in Nigeria have also reported low immunization rates; for example, a survey carried out in Sokoto, Northern Nigeria reported coverage rates as low as $7 \%[18]$.

Reports show that some other developing countries have achieved optimal immunization coverage, while others are making great strides in doing so [12]. Jani et al. [19] reported an immunization coverage rate of as high as $71.7 \%$ in a rural area in Mozambique. The consequence of suboptimal immunization coverage is low herd immunity with continued circulation of vaccine preventable diseases in the community. Herd immunity is improved by immunizing eligible children in the

community and this subsequently results in lower incidence of vaccine preventable diseases. This has been demonstrated in countries like USA, with greater than $90 \%$ coverage in which the mortality and morbidity resulting from these diseases have been significantly reduced and in some cases totally absent [20].

There were variations in the coverage rate for individual vaccines. With regard to individual vaccines, it is noteworthy that four of the antigens (DPT1, HBV1, OPV1 and HBV2) recorded 90\%, 86\%, 87\%, and $84 \%$ coverage respectively in the community studied. The coverage for BCG was $75 \%$. The proximity of the time of delivery to the vaccine schedule for obtaining the earlier vaccines may explain the high rates of coverage for these vaccines. The lowest coverage rates were recorded for measles vaccine $(65 \%)$ and yellow fever vaccine (55\%) reflecting poor compliance for vaccines scheduled for administration later in infancy. In the study population, it is customary for a newly delivered mother to spend a mandatory six weeks at home with the exception of visits to health facilities when necessary. That the majority of the mothers delivered in health facilities availed them of the opportunity to immunize their babies in the facilities. In contrast, a low rate of $37 \%$ for BCG was reported by Babalola and Lawan [21] in the northern part of Nigeria. Apart from the maternal characteristics associated with the immunization status of a child, they observed that the regularity of vaccine supply also influenced the coverage rate of BCG significantly.

From the study, $65.6 \%$ of the children were either partially immunized or did not receive any immunization. However, this absolute number reveals only the completeness of immunization and not the age appropriateness of vaccinated children. The age appropriateness of immunization is of importance in VPDs as children are prone to some infections at certain specific ages during which their attacks could result in fatal outcomes.

Drop-out rates are also measured to determine immunization programme continuity - showing the number of the children who start but fail to complete the immunization process. Among the fully immunized children, only 54\% completed their immunization before 12 months. In addition, the timeliness for receiving all vaccines was poor with HBV2 recorded as most timely at $39.9 \%$ while the least timely was DPT3, recorded as $4.7 \%$. Furthermore, the drop-out rates between different vaccines groups were all above the accepted $10 \%$ [22] as seen in figure 1 . The poor timeliness for all vaccines and high and variable drop-out rates between vaccines may be related to the presence of obstacles encountered by $72.3 \%$ of the mothers with the commonest obstacle to immunization being unavailability of vaccines $(40 \%)$ and not a lack of motivation (only $4.2 \%$ ). Therefore, one major way of achieving higher immunization coverage in Nigeria is for vaccines to be made available at all times in the routine immunization programme. Mothers also need to be educated on the immunization schedule and the need for subsequent doses of vaccines, as 'mother too busy' and 'place of vaccination too far' were also important reasons for incomplete immunization.

Concerning socioeconomic factors that predict immunization coverage, it was observed in this study that mothers with some education were more likely to have fully immunized their children compared with those that had no formal education. Higher immunization coverage was also commoner among children of mothers with higher educational status in the Mozambique study [19]. In Papua New Guinea, higher maternal education was associated with the knowledge of when to start immunizations, the frequency of visits and the diseases prevented by each vaccine [23]. The female literacy level in the study population was low as about one fifth of the mothers had no formal education. The 
female literacy level in a community needs to be optimal as educated mothers utilize child health services better (including immunization) and this has been linked positively with child survival practices [24]. Other than the level of education of mothers, exposure to other social and cultural factors may influence the utilization of immunization services.

Children from monogamous families were twice more likely to complete immunization than those from polygamous homes and children of the $1^{\text {st }}$ and $2^{\text {nd }}$ birth order than those of $3^{\text {rd }}$ order and above. Several studies have corroborated findings of a larger family size and later birth order as being associated with poor immunization status of children. This may be related to socioeconomic and domestic pressures of a large family due to time pressures and cost of transportation for each immunization for each child, especially if health care facilities are not in close proximity.

The place of delivery of children in this study was also a significant predictor of immunization, with those delivered in health care facilities being 2.3 times more likely to complete immunization. Similar findings have been reported in previous studies $[21,25,26]$, potentially due to the fact that delivery in health facilities affords mothers the opportunity to receive health education and other preventative health care services including immunization.

The limitations of the study include that with a cluster design, assumptions are made that clusters are similar to one another. However, the large number of clusters of highly dispersed settlements in both near and hard to reach areas studied which should help to reduce this bias.

\section{Conclusion}

The immunization coverage rate among children in this rural community was sub-optimal and lower dropout rates may be achieved by making vaccines readily available. High female literacy levels and delivery in health facilities need to be promoted.

\section{References}

1. Health Reform Foundation of Nigeria (2006) Nigerian Health Review: 48-49.

2. UNICEF. Immunization summary: A statistical reference.

3. Federal Office of Statistics and UNICEF (1997) The progress of Nigerian children. African Book Builders Ltd, Ibadan.

4. WHO (1997) Expanded programme on Immunization: Imaginative ways of raising immunization coverage.

5. WHO (2005) Global immunization vision and strategy 2006 - 2015. http:// whqlibdoc.who.int/hq/2005/WHO_IVB_05.05.pdf
6. WHO Immunization surveillance, assessment and monitoring: vaccine preventable diseases.

7. (1999)From the centers for Disease Control and Prevention. Impact of vaccines universally recommended for children--United States, 1900- 1998. JAMA 281 1482-1483.

8. National Population Commission and IRD/ Macro International Inc. (1999) Nigeria Demographic and Health survey. National Population Commission.

9. UNICEF (2004) Extra financial resources needed to achieve the health MDGs in Nigeria: Preliminary findings (draft 2). UNICEF, Abuja.

10. Azubuike JC, Nkanginieme KEO (2007) Paediatrics and Child health in a Tropical region. (2nd edn.) African Educational Series, Owerri.

11. Feilden Battersby Analysts (2005) The state of routine immunization services in Nigeria and reasons for current problems. FBA Health System Analysts.

12. UNICEF (2011) The State of the world's children.

13. Tove K Ryman, Vance Dietz, K Lisa Cairns (2008) Too little but not too late: Results of a literature review to improve immunization programs in developing countries. BMC Health Serv Res 8:134.

14. National Population Commission (NPC) (2007) Nigerian Population Facts and Figures.

15. WHO (2005) Immunization coverage cluster survey - Reference manual.

16. National Primary Health Care Development Agency (2010) Report on 2010 National immunization coverage survey. Abuja, Nigeria.

17. Valadez JJ, Weld LH (1992) Maternal recall error of child vaccination status in a developing nation. Am J Public Health 82: 120-122.

18. Okolo SN, Adeleke OA, Chukwu GA, Egbuaga NH, Hassan A, et al. (2003) Immunization and nutritional status survey of children in selected rural communities of Sokoto state. Nig J Paediatr 30: 123-127.

19. Jani JV, De Schacht C, Jani IV, Bjune G (2008) Risk factors for incomplete vaccination and missed opportunity for immunization in rural Mozambique. BMC Public health 8: 161.

20. WHO (2006) WHO vaccine preventable diseases monitoring system.

21. Babalola S, Lawan U (2009). Factors predicting BCG immunization status in northern Nigeria: a behavioral-ecological perspective. J Child Health Care 13 $46-62$

22. World Health Organization. Immunization profile-Nigeria.

23. USAID (2003) Immunization Essentials. A Practical field guide.

24. Freeman PA. Thompson JA, Bukenya GB (1992) Factors affecting the use of immunization among urban settlement dwellers in Papua New Guinea. P N G Med J 35: 179-185.

25. Luman ET, Barker EL, Shaw KM, McCauley MM, Buehler JW, et al. (2005) Timeliness of childhood vaccinations in the United States: days undervaccinated and number of vaccines delayed. JAMA 293: 1204-1211.

26. Oladokun RE, Lawoyin TO, Adedokun BO (2009) Immunization status and its determinants among children of female traders in Ibadan, South Western Nigeria. Afr J Med Med Sci. 38: 9-15. 